\title{
Analysis of Fecal Sludges Reveals Common Enteric Pathogens in Urban Maputo, Mozambique
}

\author{
Drew Capone, David Berendes, Oliver Cumming, Jackie Knee, Rassul Nalá, Benjamin B. Risk, \\ Christine Stauber, Kevin Zhu, and Joe Brown*
}

Cite This: Environ. Sci. Technol. Lett. 2020, 7, 889-895

Read Online

ABSTRACT: Sewage surveillance is increasingly used in public health applications; metabolites, biomarkers, and pathogens are detectable in wastewater and can provide useful information about community health. Work on this topic has been limited to wastewaters in mainly high-income settings, however. In low-income countries, where the burden of enteric infection is high, nonsewered sanitation predominates. In order to assess the utility of fecal sludge surveillance as a tool to identify the most prevalent enteric pathogens circulating among at-risk children, we collected 95 matched child stool and fecal sludge samples from household clusters sharing latrines in urban Maputo, Mozambique. We analyzed samples for 20 common enteric pathogens via

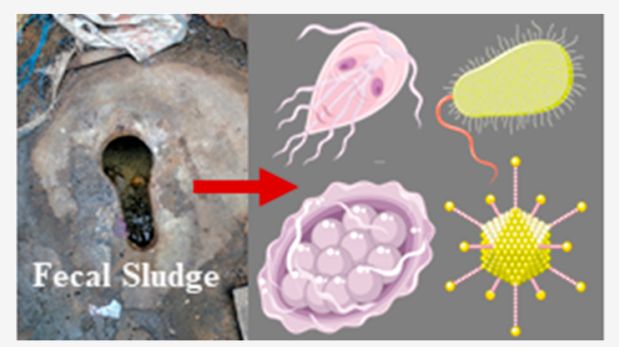
multiplex real-time quantitative PCR. Among the 95 stools matched to fecal sludges, we detected the six most prevalent bacterial pathogens (Enteroaggregative E. coli, Shigella/Enteroinvasive E. coli, Enterotoxigenic E. coli, Enteropathogenic E. coli, shiga-toxin producing E. coli, Salmonella), and all three protozoan pathogens (Giardia duodenalis, Cryptosporidium parvum, Entamoeba histolytica) in the same rank order in both matrices. We did not observe the same trend for viral pathogens or soil-transmitted helminths, however. Our results suggest that sampling fecal sludges from onsite sanitation offers potential for localized pathogen surveillance in low-income settings where enteric pathogen prevalence is high.

\section{INTRODUCTION}

Wastewater monitoring is increasingly used in community health surveillance; as a composite sample of a population's fecal waste, sewage has been shown to provide useful community-level information on biomarkers of illicit drug use, ${ }^{1}$ antimicrobial resistance, ${ }^{2,3}$ and chronic disease. ${ }^{4}$ Sewage surveillance has yielded advanced warning of viral outbreaks s, $^{5}$ and has gained increased prominence in monitoring for SARSCoV-2 in sewersheds, ${ }^{7-11}$ which is now being applied globally. Apart from poliovirus monitoring to complement eradication efforts, ${ }^{12-14}$ the method has not been widely used in low- and middle-income countries (LMICs), despite the need for better surveillance of enteric infections in high-burden settings. ${ }^{15,16}$

Although wastewater is the focus of most efforts in this area, and even lends its name to the emerging field of "wastewaterbased epidemiology" (WBE), ${ }^{17}$ onsite sanitation systems predominate in the lowest income settings. ${ }^{18}$ Such systems serve at least 1.8 billion people in LMICs, ${ }^{19}$ where sewerage has not kept pace with rapidly densifying cities. ${ }^{20,21}$ Where sewers are absent, analysis of fecal sludges from onsite systems, including shared systems which serve 630 million people, ${ }^{18}$ offers a compelling method for infection surveillance.

Direct examination of stool, serum, or other biological samples from individuals is commonly used to estimate community prevalence of infection or to identify key pathogens of interest in a given setting. ${ }^{22,23}$ For enteric pathogens shed in feces, both wastewater and fecal sludge monitoring have advantages over biological samples from individuals in being noninvasive, lower cost, and logistically less complex, including the potential to be classified as nonhuman subjects research. Compared with fecal sludges, which remain sequestered until a pit is emptied, wastewater as a matrix generally includes waste from more individuals. Therefore, wastewater may be more representative of fecal wastes in a population and provide a more current snapshot of circulating pathogens. However, wastewater may also be more dilute $^{24}$ and farther downstream from specific subpopulations of interest, like residents of urban informal communities. ${ }^{25}$ Where these subpopulations are not covered by sewers, and may subsequently be at greater risk of enteric diseases, ${ }^{23,26}$ fecal sludges offer the opportunity to concentrate surveillance efforts in limited geographic areas.

As pathogens in fecal sludges indicate previous exposures among those contributing waste, ${ }^{27}$ using fecal sludges to identify the primary enteric pathogens circulating in a community may inform how best to control them. Public health interventions including improved water, sanitation, and

Received: August 5, 2020

Revised: October 7, 2020

Accepted: October 8, 2020

Published: October 13, 2020 
hygiene (WASH); ${ }^{28}$ mass drug administration (MDA); ${ }^{29}$ and vaccination ${ }^{30}$ could thus be targeted to specific infections when and where they occur, according to their effectiveness in controlling specific pathogens.

Applying the concept of fecal waste monitoring to onsite systems in LMICs requires initial testing and validation using fecal sludges, including comparison with community infection prevalence. In fact, apart from the concurrent collection of stools and wastewater to monitor polio vaccination campaigns in Atlanta, GA, United States, ${ }^{31}$ and Havana, Cuba, ${ }^{32}$ wastewater surveillance methods have generally not been "ground truthed" by comparison with stool sample collection and analysis. Our study aim was to determine whether the most prevalent enteric pathogens in fecal sludges from shared onsite sanitation systems at compounds (clusters of multiple households sharing common outside space and sanitation) enrolled in the Maputo Sanitation (MapSan) trial $^{23,33}$ were also the most prevalent enteric pathogens in stool samples from children and infants living in these compounds. The MapSan trial was a controlled, before-and-after trial to evaluate the impact of an urban-shared sanitation intervention on enteric infection and other health outcomes in children (Text S1). We sought to assess whether analysis of fecal sludges from shared latrines can reliably identify which enteric pathogens are most common among children living in households served by them.

\section{MATERIALS AND METHODS}

Our study took place in MapSan intervention and control compounds in low-income neighborhoods of Maputo, Mozambique, 24 months after the implementation of the shared sanitation intervention. ${ }^{23,33}$ In study neighborhoods, the population density is high $(>15,000$ people per square $\mathrm{km}) .{ }^{34}$ Also, the sanitary conditions are inadequate, ${ }^{23}$ and at study baseline, $86 \%$ of all children tested positive for one or more enteric infection. ${ }^{23}$ We used convenience sampling to collect fecal sludges from 95 MapSan compounds 1-10 days following stool collection of the enrolled child $(n=95)$ (October 2017-April 2018). ${ }^{23,33}$ Methods for stool collection were previously described elsewhere. ${ }^{23}$ We obtained children's age and household socioeconomic characteristics from the MapSan 24 month survey data set. ${ }^{35}$

Because pit latrines produce thicker sludge than septic tanks and because sludges in septic tanks separate into distinct layers of scum, liquids, and solids, ${ }^{36}$ we used a unique protocol for each system type. For sampling pit latrines, we adapted a Sludge Nabber (Nasco, Fort Atkinson, WI) with a plastic tubing cover and a $50 \mathrm{~mL}$ centrifuge tube (Figure S1, Text S2). For septic tanks, we used a modified Wheaton Sub-Surface Sampler I system (Fisher Scientific, Waltham, MA, USA) with a plastic insert to hold a $50 \mathrm{~mL}$ centrifuge tube (Figure S1, Text S2). All fecal sludge samples were stored on ice for transport, aliquoted into $2 \mathrm{~mL}$ cryovials within $6 \mathrm{~h}$ of collection and stored at $-80{ }^{\circ} \mathrm{C}$ at the Mozambican National Institute of Health. All samples were shipped from Maputo, Mozambique, to Atlanta, GA, USA, on dry ice $\left(-80^{\circ} \mathrm{C}\right)$ with temperature monitoring for molecular analysis.

Sample Processing. For total nucleic acid extraction from $100 \mathrm{mg}$ of stools and fecal sludges (wet weight), we followed a pretreatment protocol validated for multiplex PCR (Text S3). ${ }^{23,37,38}$ We proceeded with extraction following the manufacturer's protocol for the QIAamp 96 Virus QIAcube HT Kit, which we automated on the QIAcube (Qiagen,
Hilden, Germany). We included MS2 as an extraction control. To determine the solids content of fecal sludges, we adapted the oven drying method (Text S3). ${ }^{39}$

Recent advances in multiplex PCR assays enable rapid and simultaneous detection of pathogens from a variety of samples types, ${ }^{23,37,40}$ providing a useful molecular method for pathogen surveillance. One such platform, the TaqMan array card (TAC), is a 384-well microfluidic card that can be customized using validated assays ${ }^{40-42}$ and therefore is suited to detect a wide range of pathogens that may vary by setting. ${ }^{22}$ We tested all samples using a custom TAC (ThermoFisher Scientific, Waltham, MA) that tested for 20 enteric pathogens, including 10 bacteria, five viruses, three protozoa, and two soiltransmitted helminths (STH) in duplicate (Tables S1 and S2, Text S4). We included positive and negative controls on each TAC (Text S4). We visually compared exponential curves and multicomponent plots with positive control plots to validate positive amplification. Samples that exhibited positive amplification in either duplicate well before a quantification cycle $(\mathrm{Cq})$ of 40 were considered positive (Table S3).

\section{DATA ANALYSIS}

Predictors of the Number of Pathogens in Stools and Fecal Sludges. To understand what variables were associated with the number of pathogens in stools and sludges, we investigated how children's ages, compound wealth, compound population, and type of onsite sanitation predicted the number of pathogens in each matrix. Our response variables included the number of detected pathogenic bacteria (range: 0-10), viruses $(0-5)$, protozoa $(0-3)$, and STHs $(0-2)$ in stools and fecal sludges. Exposure variables representing potential contributors to the number of pathogens were a one-quartile increase in wealth score, ${ }^{43}$ a 10 -person increase in compound population, and pour-flush to septic tank sanitation compared to pit latrines. Also, specifically for stools, we included a categorical variable for a child's age $(1-23,24-47$, or $48-82$ months). To account for missing data in the child's age variable, we used multiple imputation with chained equations (Text S5). ${ }^{44-46}$

We fit generalized linear models (GLM, Poisson regression with log link) to calculate unadjusted and adjusted prevalence ratios (PR, aPR) (Text S5). For this study, we define prevalence ratios as the number of pathogenic bacteria, viruses, protozoa, or STHs for an exposure variable compared to the reference. We fit models including all exposure variables simultaneously for stools and sludges, did not include any additional confounders in stool models (Figure S2), and included a sample's $\log _{10}$-transformed fecal sludge solids content as an additional covariate in fecal sludge models (Figure S3, Text S2). Recognizing our analysis generated multiple models, we applied a false discovery rate correction across taxa. ${ }^{47}$ We analyzed data in $\mathrm{R}$ version 4.0.0 ( $\mathrm{R}$ Foundation for Statistical Computing, Vienna, Austria).

Comparison of Matched Stools and Fecal Sludges. We used the presence of individual pathogens to compare stools and sludges. For matched samples, we used the Jaccard similarity coefficient ${ }^{48}$ (e.g., intersection of detections over the union) because it excludes instances of nondetects in both matrices which would bias the similarity between sludges and stools upward for rare pathogens. For example, out of our 95 samples, if we were to detect an individual pathogen in both a stool and the matched fecal sludge sample 40 times, only in 
Table 1. Pathogens in Stools and Fecal Sludges Sorted by Prevalence in Stool (Third Column) ${ }^{a}$

\begin{tabular}{|c|c|c|c|c|c|}
\hline No. & Pathogen & $\begin{array}{l}\text { Stool }(n=95) \\
\quad(95 \% \mathrm{CI})\end{array}$ & $\begin{array}{l}\text { Sludge }(n=95) \\
\quad(95 \% \mathrm{CI})\end{array}$ & $\begin{array}{l}\text { Jaccard similarity } \\
\text { coefficient }^{b}(J)\end{array}$ & $\begin{array}{l}\text { Stool detections with detection in } \\
\text { matched sludge }\end{array}$ \\
\hline \multicolumn{6}{|c|}{ Bacteria } \\
\hline 1 & EAEC & $67 \%(58 \%, 77 \%)$ & $82 \%(74 \%, 90 \%)$ & $65 \%(56 / 96)$ & $88 \%(56 / 64)$ \\
\hline 2 & Shigella/EIEC & $51 \%(40 \%, 61 \%)$ & $76 \%(67 \%, 84 \%)$ & $45 \%(37 / 83)$ & $77 \%(37 / 48)$ \\
\hline 3 & $\operatorname{ETEC}(S T / L T)$ & $38 \%(28 \%, 48 \%)$ & $56 \%(46 \%, 66 \%)$ & $33 \%(22 / 66)$ & $63 \%(22 / 35)$ \\
\hline 4 & EPEC & $34 \%(24 \%, 43 \%)$ & $39 \%(29 \%, 49 \%)$ & $19 \%(11 / 57)$ & $35 \%(11 / 31)$ \\
\hline 5 & STEC $(s t x 1 / s t x 2)$ & $6.3 \%(1.4 \%, 11 \%)$ & $15 \%(7.6 \%, 22 \%)$ & $0 \%(0 / 20)$ & $0 \%(0 / 6)$ \\
\hline 6 & Salmonella & $6.3 \%(1.4 \%, 11 \%)$ & $8.4 \%(2.8 \%, 14 \%)$ & $0 \%(0 / 14)$ & $0 \%(0 / 6)$ \\
\hline 7 & Campylobacter jejuni/coli & $5.3 \%(0.75 \%, 9.8 \%)$ & $4.2 \%(0 \%, 8.3 \%)$ & $0 \%(0 / 9)$ & $0 \%(0 / 5)$ \\
\hline 8 & C. difficile & $3.4 \%(0 \%, 6.7 \%)$ & $7.4 \%(2.1 \%, 13 \%)$ & $0 \%(0 / 10)$ & $0 \%(0 / 3)$ \\
\hline 9 & Vibrio cholerae & $0 \%$ & $1.1 \%(0 \%, 3.1 \%)$ & $0 \%(0 / 1)$ & \\
\hline 10 & Yersinia spp. & $0 \%$ & $2.1 \%(0 \%, 5.0 \%)$ & $0 \%(0 / 2)$ & \\
\hline \multicolumn{6}{|l|}{ Viruses } \\
\hline 1 & Sapovirus I/II/IV/V & $12 \%(5.1 \%, 18 \%)$ & $47 \%(37 \%, 57 \%)$ & $17 \%(8 / 48)$ & $72 \%(8 / 11)$ \\
\hline 2 & Norovirus GI/GII & $11 \%(4.4 \%, 17 \%)$ & $58 \%(48 \%, 68 \%)$ & $8.3 \%(5 / 60)$ & $50 \%(5 / 10)$ \\
\hline 3 & Astrovirus & $8.4 \%(2.8 \%, 14 \%)$ & $63 \%(53 \%, 73 \%)$ & $9.7 \%(6 / 62)$ & $75 \%(6 / 8)$ \\
\hline 4 & Adenovirus 40/41 & $4.2 \%(0 \%, 8.3 \%)$ & $44 \%(34 \%, 54 \%)$ & $7.0 \%(3 / 43)$ & $75 \%(3 / 4)$ \\
\hline 5 & Rotavirus A & $1.1 \%(0 \%, 3.1 \%)$ & $8.4 \%(2.8 \%, 14 \%)$ & $13 \%(1 / 8)$ & $100 \%(1 / 1)$ \\
\hline \multicolumn{6}{|c|}{ Protozoa } \\
\hline 1 & Giardia duodenalis & $64 \%(55 \%, 74 \%)$ & $86 \%(79 \%, 93 \%)$ & $63 \%(55 / 88)$ & $90 \%(55 / 61)$ \\
\hline 2 & Cryptosporidium parvum & $12 \%(5.1 \%, 18 \%)$ & $24 \%(16 \%, 33 \%)$ & $9.7 \%(3 / 31)$ & $27 \%(3 / 11)$ \\
\hline 3 & Entamoeba histolytica & $1.1 \%(0 \%, 3.1 \%)$ & $12 \%(5.1 \%, 18 \%)$ & $9.1 \%(1 / 11)$ & $100 \%(1 / 1)$ \\
\hline \multicolumn{6}{|l|}{ STHs } \\
\hline 1 & Trichuris trichiuria & $42 \%(32 \%, 52 \%)$ & $65 \%(56 \%, 75 \%)$ & $42 \%(30 / 72)$ & $75 \%(30 / 40)$ \\
\hline 2 & Ascaris lumbricoides & $32 \%(22 \%, 41 \%)$ & $88 \%(82 \%, 95 \%)$ & $31 \%(27 / 87)$ & $90 \%(27 / 30)$ \\
\hline
\end{tabular}

${ }^{a}$ A bold number in the first column indicates the pathogen was detected in the same rank order in stools and fecal sludges. C. difficile: Clostridium difficile. EAEC: Enteroaggregative E. coli. EIEC: Enteroinvasive E. coli. ETEC: Enterotoxigenic E. coli. EPEC: Enteropathogenic E. coli. STEC: shigatoxin producing E. coli. ${ }^{b}$ Size of the intersection of matched detections divided by the size of the union of detections. For example, we detected Giardia in both stool and the matched fecal sludge sample 55 times, only in stool six times, only in fecal sludge 27 times, and did not detect Giardia in either sample seven times, e.g., $J_{\text {Giardia }}=(55) /(55+6+27)=63 \%$

stool 10 times, only in sludge 30 times, and in neither sample 15 times, the Jaccard similarity coefficient is $50 \%$ (eq 1 ).

$$
J_{X}=40 \div(40+10+30)=50 \%
$$

\section{RESULTS AND DISCUSSION}

Pathogens Detected in Stools. We collected stools from 95 children who ranged in age from 1 to 82 months (median = 37 months, mean $=39$ months, $\mathrm{SD}=21$ months). In stools, we most often detected pathogenic bacteria (96\%, [91/95]), followed by protozoa (68\%, [65/95]), STHs (53\%, [50/95]), and viruses (28\%, [27/95]) (Tables S4 and S5). Out of 20 pathogens, we detected a mean of 3.9 pathogens per stool on average (mean $=3.9$ out of 20 , median $=4.0$, range $=0-9$ ), which is similar to children living in other LMICs. ${ }^{22}$ Adjusted for wealth score, compound population, and type of onsite sanitation, we found that stools from the oldest children (4882 months) had no difference in the number of pathogenic bacteria $(\mathrm{aPR}=1.3,95 \%$ CI $[0.87,1.9])$ or protozoa $(\mathrm{aPR}=$ $1.3[0.66,2.6])$ but observed a lower number of viruses $(\mathrm{aPR}=$ $0.17[0.05,0.57])$ and a greater number of helminths $(\mathrm{aPR}=$ $4.3[1.8,10])$ compared to the youngest children (1-23 months) (Table 1). This subsample of 95 stools collected from children in the MapSan cohort yielded consistent estimates of prevalence with the MapSan trial baseline $(n=759)^{23}$ conducted 24-36 months earlier. We detected all pathogens in each taxa in the same rank order except for Campylobacter and STEC, which were infrequently detected at the MapSan baseline ( $8 \%$ and $2 \%$ prevalence, respectively). ${ }^{23}$

Pathogens Detected in Fecal Sludges. We collected 52 fecal sludge samples from pour-flush to septic tank sanitation systems and 43 from pit latrines. The mean number of people per compound was $15(\mathrm{SD}=7$, median $=13$, range $=4-38)$. In fecal sludges we commonly detected all types of pathogens (bacteria: 95\%, [90/95], STHs: 95\%, [90/95], viruses: 91\%, [86/95], protozoa: $88 \%,[84 / 95]$ ) and in high number (mean $=7.9$ out of 20 , median $=8.0$, range $=0-14)$. In addition, adjusted for wealth score, compound population, and fecal sludge solids content, we found septic tank systems were associated with a reduced number of bacterial pathogens (aPR $=0.66,95 \%[0.50,0.86])$ compared to pit latrines (Table S6).

Stools and Fecal Sludges Comparison. Among all stools and fecal sludges, the six most frequently detected bacterial pathogens were the same in both matrices and were detected in the same rank order (Table 1). We did not observe the same pattern for the viral pathogens, and the prevalence of all viruses was much greater in fecal sludges than in stools. We detected all three protozoan pathogens in the same order of prevalence in stools and fecal sludges. We detected Trichuris more frequently than Ascaris in stools but detected Ascaris more frequently than Trichuris in fecal sludges. Stratifying our analysis by sanitation type (pit latrines and septic tanks), the six most frequently detected bacteria were different for pit 
latrines and septic tanks, but for each type of infrastructure, the six most frequently detected bacterial pathogens were still detected in the same rank order as matched stools (Table S7).

Intracompound Stool and Fecal Sludge Comparison. We detected every pathogen except Campylobacter more frequently in fecal sludges than in stools. Because we detected pathogens more frequently in sludges than in stools, the Jaccard similarity coefficients were highest among pathogens with the greatest prevalence in stools, lowest for pathogens with the lowest prevalence in stools, and zero for all bacterial pathogens detected in less than $10 \%$ of stools (Table 1). For bacteria, protozoa, and STHs, matched detections in stools and fecal sludges tended to increase with increased prevalence in stools; in at least half of the instances, all viruses detected in stools were detected in matched fecal sludges (Table 1). Specifically, when EAEC, rotavirus A, Giardia duodenalis, Entamoeba hystolytica, and Ascaris lumbricoides were detected in a stool, they were also detected in the matched sludge at least $80 \%$ of the time. These observations suggest that, for these pathogens, sludges may be a useful proxy for prevalence of shedding among children in this setting.

Intercompound vs Intracompound Interpretation. The same rank order of bacterial and protozoan pathogens in fecal sludges from pit latrines and septic tanks compared with pathogens in stools provides evidence that fecal sludges may be a reliable end point for enteric pathogen surveillance in low-income urban settings for at least some pathogens. However, the Jaccard similarity coefficients for 18 of the 20 pathogens assessed were less than $50 \%$, indicating infrequent codetection of pathogens in matched stools and sludges. Accordingly, surveillance of onsite sanitation systems may better provide a community-level snapshot of circulating pathogens, while being a poor predictor of individual prevalence.

While substantial overlap in gut microbiota has been observed among household members in previous studies, ${ }^{49,50}$ suggesting that gut pathogen carriage may be comparable among those sharing living spaces, stool samples from any individual may not be representative of pathogens shared by others. We compared single stool samples from children with fecal sludges from latrines serving an average of 15 people, including adults. Of the 20 pathogens assessed, the number of detections in fecal sludges $(n=7.9)$ was twice that of stools $(n$ $=3.9$ ), reflective of the fact that sludge represents a composite of multiple individuals' feces. Indeed, the total number of detects would necessarily increase unless pathogens were evenly distributed across all individuals. Furthermore, some children's stools may not have been deposited in latrines. ${ }^{51}$ These factors may explain why we did not observe high Jaccard similarity coefficients between fecal sludges and individual stools.

Factors Impacting Pathogen Detection. Variations in the detected order and prevalence between stools and sludges-especially among viral targets-suggests additional work is needed to interpret pathogen detection based on shedding rates in stool, ${ }^{52,53}$ fate and transport, ${ }^{53-55}$ biological and environmental factors, ${ }^{53-55}$ assay limits of detection, and potential differences in nucleic acid extraction kit efficiencies. Such factors may explain why we did not detect viruses and STHs in fecal sludge in the same rank order as in stool samples. Ascaris can persist longer in the environment than Trichuris, ${ }^{53}$ but MDA to treat helminthiasis is less effective for Trichuris than Ascaris. ${ }^{56}$ Children enrolled in the MapSan trial received single dose of albendazole before the 24 month follow-up period, which may explain why we detected Trichuris more often in stools but Ascaris more often in sludges. While we detected bacterial pathogens in the same rank order in stools and sludges, environmental dynamics such as die-off and regrowth ${ }^{57}$ could produce a different result in other settings. During viral gastroenteritis, viruses are shed in high concentration $\left(\leq 10^{10}-10^{12}\right.$ per gram feces),,$^{52,53}$ and viral infections were associated with symptomatic diarrhea in Maputo. ${ }^{11}$ Watery diarrheal stools may result in greater spatial distribution inside a latrine compared to solid stools and may explain why we often detected viruses in sludges despite a relatively lower prevalence in stools. As expected from previous studies in Maputo $^{23}$ and Manhiça, Mozambique, ${ }^{22,58}$ we observed increasing age was associated with a reduced number of pathogenic viruses and a greater number of pathogenic protozoa (although not after correcting for multiple comparisons) and STHs. As children age, their mobility and consumption of food and drinking water increases, which increases infection risks. However, as children in LMICs begin walking on their own, their contact with other people may decrease, potentially decreasing their infection risk from viruses spread via person-to-person transmission. ${ }^{59}$ Considering sludges are a composite from individuals with a wider range of ages than the stools we measured, it is logical the rank order of viruses and STHs in sludges may not align with the rank order of stools from young children alone, since the pathogen shedding profile in infants and children may differ from others also contributing waste to the latrine. In addition, the difference in prevalence of the three pathogenic protozoa in stools was large and may have limited the potential for change in the rank order detection from stool to sludge.

As a cross-sectional study, we were unable to assess the sensitivity of pathogen signals to changes in disease prevalence or incidence over time, although this is a logical next step for further research. Longitudinal studies of fecal sludges in LMICs are required to assess such changes over time, including utility in detecting disease outbreaks ${ }^{60}$ and to assess if sludges are useful for health impact assessment in water, sanitation, and hygiene (WASH); vaccines; and MDA intervention trials. We observed the same rank order prevalence for bacterial and protozoan pathogens from both pit latrines and septic tanks, except we detected fewer bacterial pathogens in septic tank sludges, and the six most prevalent bacterial pathogens were different between the two systems. Stratification of data by onsite sanitation infrastructure type may provide a helpful nuance to understanding circulating pathogens. This level of detail suggests that fecal sludge surveillance may offer greater insight into circulating pathogens at a finer spatial scale compared to dilute wastewater samples which may be more representative of an entire sewershed.

Future work is needed before fecal sludge surveillance can be scaled and used in LMICs. First, we collected one sample per sanitation system in a $50 \mathrm{~mL}$ centrifuge tube at a single point just below the surface of the solids. It is plausible the sludges we collected represented older feces than those at the solids surface and may offer a longer-term snapshot of community infections compared to wastewater. More work is needed to standardize sample collection techniques, which may include collecting and homogenizing a larger volume of sludge from each system. Second, quantitative work is needed to assess differences in pathogen concentration and nucleic acid recovery between stools and sludges and to reconcile potential 
differences in limits of detection. Such concentration data would be helpful for risk assessment modeling, ${ }^{61}$ to assess the sensitivity of signals in sludges to the number of individuals contributing waste, and to monitor temporal changes. Third, decay experiments are needed to characterize pathogen persistence in fecal sludges, including for pathogen nucleic acids that would typically be detected via methods similar to those we used in this study. Finally, compared with PCR-based methods, metagenomics should be explored as it offers an unbiased approach to assess the microbial community in onsite sanitation systems and may be desired for comparison with global wastewater surveillance efforts. ${ }^{15}$ Applying these methods for tracking specific pathogens may be limited by comparatively high detection limits and a lack of capacity for analysis in high-burden settings, however.

The ability to capture the relative frequency of enteric pathogens in a community-without the logistical constraints and invasive nature of stool collection-offers the opportunity to rapidly gather novel and actionable information regarding community health. In urban settings with limited resources, surveillance of fecal sludges may be a cheap and scalable option to monitor emerging pathogens. ${ }^{11}$ Applying the principles of wastewater-based surveillance to areas covered by onsite systems is promising, but future work is needed to standardize methods and better characterize and interpret observed pathogen signals. Advances in surveillance where data are limited may help develop and prioritize appropriate and effective strategies to reduce infection risk.

\section{ASSOCIATED CONTENT}

\section{s) Supporting Information}

The Supporting Information is available free of charge at https://pubs.acs.org/doi/10.1021/acs.estlett.0c00610.

Figure S1: Photos of latrine samplers. Text S1: Description of MapSan trial. Text S2: Methodology for fecal sludge collection. Text S3: Methodology for total nucleic acid extraction from fecal sludge and stool. Text S4: Custom TaqMan Array Card (TAC). Table S1: TAC and GPP comparison. Table S2: Assays used on the custom TAC. Table S3: Interpretation of gene targets on the TAC. Text S5: Regression models. Figure S2: DAGs of stool models. Figure S3: DAGs of sludge models. Table S4: Summary of pathogens in stools and sludges. Table S5: Average $\mathrm{Cq}$ values. Table S6: Associations between variables and the number of detected pathogenic bacteria, viruses, protozoa, or STHs in stools and sludges. Table S7: Pathogen detection data disaggregated by sanitation infrastructure (septic tanks and latrines). (PDF)

\section{AUTHOR INFORMATION}

\section{Corresponding Author}

Joe Brown - Civil and Environmental Engineering, Georgia Institute of Technology, Atlanta, Georgia 30332, United States; Department of Environmental Sciences and Engineering, Gillings School of Global Public Health, University of North Carolina at Chapel Hill, Chapel Hill, North Carolina 27599-7431, United States; 이이. orcid.org/0000-0002-5200-4148; Phone: +1 919360-8752; Email: joebrown@unc.edu

\section{Authors}

Drew Capone - Civil and Environmental Engineering, Georgia Institute of Technology, Atlanta, Georgia 30332, United States; Department of Environmental Sciences and Engineering, Gillings School of Global Public Health, University of North Carolina at Chapel Hill, Chapel Hill, North Carolina 27599-7431, United States

David Berendes - Waterborne Disease Prevention Branch, Division of Foodborne, Waterborne, and Environmental Diseases, National Center for Emerging Zoonotic and Infectious Diseases, Centers for Disease Control and Prevention, Atlanta, Georgia 30329, United States

Oliver Cumming - Department of Disease Control, Faculty of Infectious and Tropical Diseases, London School of Hygiene \& Tropical Medicine, WC1E 7HT London, United Kingdom

Jackie Knee - Department of Disease Control, Faculty of Infectious and Tropical Diseases, London School of Hygiene \& Tropical Medicine, WC1E 7HT London, United Kingdom; (1) orcid.org/0000-0002-0834-8488

Rassul Nalá - Ministério da Saúde, Instituto Nacional de Saúde Maputo, Maputo, Mozambique

Benjamin B. Risk - Department of Biostatistics and Bioinformatics, Emory University, Atlanta, Georgia 30322, United States

Christine Stauber - School of Public Health, Georgia State University, Atlanta, Georgia 30302, United States; (1) orcid.org/0000-0002-2226-0976

Kevin Zhu - Civil and Environmental Engineering, Georgia Institute of Technology, Atlanta, Georgia 30332, United States

Complete contact information is available at: https://pubs.acs.org/10.1021/acs.estlett.0c00610

\section{Notes}

The findings and conclusions in this report are those of the authors and do not necessarily represent the official position of the Centers for Disease Control and Prevention.

The authors declare no competing financial interest.

\section{ACKNOWLEDGMENTS}

The authors are very grateful for Trent Sumner's contributions to the design of the fecal sludge sampling methods used in this study. We are also grateful for Bacelar Muneme and Tesse Bijleveld who assisted with the fecal sludge sampling. This study was funded by the United States Agency for International Development (www.usaid.gov) under Translating Research into Action (Cooperative Agreement No. GHS-A00-09-00015-00) and the Bill and Melinda Gates Foundation (www.gatesfoundation.org) grant OPP1137224. The funders had no role in study design, data collection and analysis, decision to publish, or preparation of the manuscript.

\section{REFERENCES}

(1) Thomas, K. V.; Bijlsma, L.; Castiglioni, S.; Covaci, A.; Emke, E.; Grabic, R.; Hernández, F.; Karolak, S.; Kasprzyk-Hordern, B.; Lindberg, R. H.; et al. Comparing Illicit Drug Use in 19 European Cities through Sewage Analysis. Sci. Total Environ. 2012, 432, 432439.

(2) Hendriksen, R. S.; Munk, P.; Njage, P.; van Bunnik, B.; McNally, L.; Lukjancenko, O.; Roder, T.; Nieuwenhuijse, D.; Pedersen, S. K.; Kjeldgaard, J.; Kaas, R. S.; Clausen, P. T. L. C.; Vogt, J. K.; Leekitcharoenphon, P.; van de Schans, M. G. M.; Zuidema, T.; de Roda Husman, A. M.; Rasmussen, S.; Petersen, B.; Amid, C.; Cochrane, G.; Sicheritz-Ponten, T.; Schmitt, H.; Alvarez, J. R. M.; 
Aidara-Kane, A.; Pamp, S. J.; Lund, O.; Hald, T.; Woolhouse, M.; Koopmans, M. P.; Vigre, H.; Petersen, T. N.; Aarestrup, F. M. Global Monitoring of Antimicrobial Resistance Based on Metagenomics Analyses of Urban Sewage. Nat. Commun. 2019, 10 (1), na.

(3) The Underworlds Book; MIT Senseable City Laboratory, Massachusetts Institute of Technology, 2019.

(4) Santos, J. M.; Jurban, M.; Kim, H. Could Sewage Epidemiology Be a Strategy to Assess Lifestyle and Wellness of a Large Scale Population? Med. Hypotheses 2015, 85 (4), 408-411.

(5) Hellmér, M.; Paxéus, N.; Magnius, L.; Enache, L.; Arnholm, B.; Johansson, A.; Bergström, T.; Norder, H. Detection of Pathogenic Viruses in Sewage Provided Early Warnings of Hepatitis A Virus and Norovirus Outbreaks. Appl. Environ. Microbiol. 2014, 80 (21), 67716781.

(6) Smith, D. B.; Paddy, J. O.; Simmonds, P. The Use of Human Sewage Screening for Community Surveillance of Hepatitis E Virus in the UK. J. Med. Virol. 2016, 88 (5), 915-918.

(7) Medema, G.; Heijnen, L.; Elsinga, G.; Italiaander, R.; Brouwer, A. Presence of SARS-Coronavirus-2 RNA in Sewage and Correlation with Reported COVID-19 Prevalence in the Early Stage of the Epidemic in The Netherlands. Environ. Sci. Technol. Lett. 2020, 7, 511.

(8) Silverman, A. I.; Boehm, A. B. Systematic Review and MetaAnalysis of the Persistence and Disinfection of Human Coronaviruses and Their Viral Surrogates in Water and Wastewater. Environ. Sci. Technol. Lett. 2020, 7, 544.

(9) Ahmed, W.; Angel, N.; Edson, J.; Bibby, K.; Bivins, A.; O’Brien, J. W.; Choi, P. M.; Kitajima, M.; Simpson, S. L.; Li, J.; et al. First Confirmed Detection of SARS-CoV-2 in Untreated Wastewater in Australia: A Proof of Concept for the Wastewater Surveillance of COVID-19 in the Community. Sci. Total Environ. 2020, 728, 138764.

(10) Bivins, A.; North, D.; Ahmad, A.; Ahmed, W.; Alm, E.; Been, F.; Bhattacharya, P.; Bijlsma, L.; Boehm, A. B.; Brown, J.; et al. Wastewater-Based Epidemiology: Global Collaborative to Maximize Contributions in the Fight Against COVID-19. Environ. Sci. Technol. 2020, 54 (13), 7754-7757.

(11) Street, R.; Malema, S.; Mahlangeni, N.; Mathee, A. Wastewater Surveillance for Covid-19: An African Perspective. Sci. Total Environ. 2020, 743, 140719.

(12) Anis, E.; Kopel, E.; Singer, S.; Kaliner, E.; Moerman, L.; MoranGilad, J.; Sofer, D.; Manor, Y.; Shulman, L.; Mendelson, E.; et al. Insidious Reintroduction of Wild Poliovirus into Israel, 2013. Eurosurveillance 2013, 18 (38), 20586.

(13) Lickness, J. S.; Gardner, T.; Diop, O. M.; Chavan, S.; Jorba, J.; Ahmed, J.; Gumede, N.; Johnson, T.; Butt, O.; Asghar, H.; et al. Surveillance to Track Progress Toward Polio Eradication Worldwide, 2018-2019. MMWR. Morb. Mortal. Wkly. Rep. 2020, 69 (20), 623-629.

(14) Hovi, T.; Shulman, L. M.; Van Der Avoort, H.; Deshpande, J.; Roivainen, M.; De Gourville, E. M. Role of Environmental Poliovirus Surveillance in Global Polio Eradication and Beyond. Epidemiol. Infect. 2012, 140 (1), 1-13.

(15) Aarestrup, F. M.; Woolhouse, M. E. J. Using Sewage for Surveillance of Antimicrobial Resistance. Science (Washington, DC, $U$. S.) 2020, 367 (6478), 630-632.

(16) Andrews, J. R; Yu, A. T; Saha, S.; Shakya, J.; Aiemjoy, K.; Horng, L.; Qamar, F.; Garrett, D.; Baker, S.; Saha, S.; Luby, S. P; et al. Environmental Surveillance as a Tool for Identifying High-Risk Settings for Typhoid Transmission. Clin. Infect. Dis. 2020, 71, S71S78.

(17) Zuccato, E.; Chiabrando, C.; Castiglioni, S.; Bagnati, R.; Fanelli, R. Estimating Community Drug Abuse by Wastewater Analysis. Environ. Health Perspect. 2008, 116 (8), 1027-1032.

(18) Children's Fund Joint Monitoring Programme for Water Supply Sanitation and Hygiene. Progress on Household Drinking Water, Sanitation and Hygiene 2000-2017. Special Focus on Inequalities; World Health Organization and United Nations: New York, 2019.

(19) Berendes, D. M.; Sumner, T. A.; Brown, J. M. Safely Managed Sanitation for All Means Fecal Sludge Management for at Least 1.8
Billion People in Low and Middle Income Countries. Environ. Sci. Technol. 2017, 51 (5), 3074-3083.

(20) Satterthwaite, D.; Beard, V. A.; Mitlin, D.; Du, J. Untreated and Unsafe: Solving the Urban Sanitation Crisis in the Global South; Washington, DC, 2019.

(21) McGranahan, G. Realizing the Right to Sanitation in Deprived Urban Communities: Meeting the Challenges of Collective Action, Coproduction, Affordability, and Housing Tenure. World Dev 2015, $68,242-253$.

(22) Liu, J.; Platts-Mills, J. A.; Juma, J.; Kabir, F.; Nkeze, J.; Okoi, C.; Operario, D. J.; Uddin, J.; Ahmed, S.; Alonso, P. L.; et al. Use of Quantitative Molecular Diagnostic Methods to Identify Causes of Diarrhoea in Children: A Reanalysis of the GEMS Case-Control Study. Lancet 2016, 388 (10051), 1291-1301.

(23) Knee, J.; Sumner, T.; Adriano, Z.; Berendes, D.; de Bruijn, E.; Schmidt, W.-P.; Nalá, R.; Cumming, O.; Brown, J. Risk Factors for Childhood Enteric Infection in Urban Maputo, Mozambique: A Cross-Sectional Study. PLoS Neglected Trop. Dis. 2018, 12 (11), No. e0006956.

(24) Strande, L.; Ronteltap, M.; Brdjanovic, D. Faecal Sludge Quantification, Characterisation and Treatment Objectives. In Faecal Sludge Management: Systems Approach for Implementation and Operation; IWA Publishing: London, UK, 2014; pp 19-44.

(25) The Challenge of Slums - Global Report on Human Settlements; Un-Habitat, 2003.

(26) Barreto, M. L.; Genser, B.; Strina, A.; Teixeira, M. G.; Assis, A. M. O.; Rego, R. F.; Teles, C. A.; Prado, M. S.; Matos, S. M.; Santos, D. N.; et al. Effect of City-Wide Sanitation Programme on Reduction in Rate of Childhood Diarrhoea in Northeast Brazil: Assessment by Two Cohort Studies. Lancet 2007, 370 (9599), 1622-1628.

(27) Brown, J.; Cumming, O. Stool-Based Pathogen Detection Offers Advantages as an Outcome Measure for Water, Sanitation, and Hygiene Trials. Am. J. Trop. Med. Hyg. 2020, 102 (2), 260-261.

(28) Korich, D. G.; Mead, J. R.; Madore, M. S.; Sinclair, N. A.; Sterling, C. R. Effects of Ozone, Chlorine Dioxide, Chlorine, and Monochloramine on Cryptosporidium Parvum Oocyst Viability. Appl. Environ. Microbiol. 1990, 56 (5), 1423-1428.

(29) Webster, J. P.; Molyneux, D. H.; Hotez, P. J.; Fenwick, A. The Contribution of Mass Drug Administration to Global Health: Past, Present and Future. Philos. Trans. R. Soc., B 2014, 369 (1645), 20130434.

(30) Madhi, S. A.; Cunliffe, N. A.; Steele, D.; Witte, D.; Kirsten, M.; Louw, C.; Ngwira, B.; Victor, J. C.; Gillard, P. H.; Cheuvart, B. B.; et al. Effect of Human Rotavirus Vaccine on Severe Diarrhea in African Infants. N. Engl. J. Med. 2010, 362 (4), 289-298.

(31) Gelfand, H. M.; Holguin, A. H.; Feldman, R. A. CommunityWide Type 3 Oral Poliovirus Vaccination in Atlanta, Ga., 1961: Medical and Virologic Results of an Epidemic Prevention Program. JAMA J. Am. Med. Assoc. 1962, 181 (4), 281-289.

(32) Lago, P. M.; Gary, H. E.; Pérez, L. S.; Cáceres, V.; Olivera, J. B.; Puentes, R. P.; Corredor, M. B.; Jímenez, P.; Pallansch, M. A.; Cruz, R. G. Poliovirus Detection in Wastewater and Stools Following an Immunization Campaign in Havana, Cuba. Int. J. Epidemiol. 2003, 32 (5), 772-777.

(33) Brown, J.; Cumming, O.; Bartram, J.; Cairncross, S.; Ensink, J.; Holcomb, D.; Knee, J.; Kolsky, P.; Liang, K.; Liang, S.; Nala, R.; Norman, G.; Rheingans, R.; Stewart, J.; Zavale, O.; Zuin, V.; Schmidt, W.-P.; et al. A Controlled, before-and-after Trial of an Urban Sanitation Intervention to Reduce Enteric Infections in Children: Research Protocol for the Maputo Sanitation (MapSan) Study, Mozambique. BMJ. Open 2015, 5 (6), e008214-e008215.

(34) Spatial Planning for Urban Sanitation and Water; WaterAid: Maputo, Mozambique, 2013.

(35) Knee, J. S. Quantifying the Impact of an Urban Onsite Shared Sanitation Intervention on Child Health in Maputo, Mozambique: The MapSan Trial; Georgia Institute of Technology, 2019.

(36) Niwagaba, C. B.; Mbeguere, M.; Strande, L. Faecal Sludge Quantification: Characterisation and Treatment Objectives, 2014. 
(37) Farling, S.; Rogers, T.; Knee, J. S.; Tilley, E. A.; Brown, J.; Deshusses, M. A. Bioaerosol Emissions Associated with Pit Latrine Emptying Operations. Sci. Total Environ. 2019, 648, 1082-1086.

(38) Capone, D.; Ferguson, A.; Gribble, M. O.; Brown, J. Open Defecation Sites, Unmet Sanitation Needs, and Potential Sanitary Risks in Atlanta Georgia 2017-2018. Am. J. Public Health 2018, 108 (9), 1238-1240.

(39) D-2216-98 Standard Test Method for Laboratory Determination of Water (Moisture) Content of Soil and Rock by Mass; ASTM, 1998.

(40) Liu, J.; Gratz, J.; Amour, C.; Kibiki, G.; Becker, S.; Janaki, L.; Verweij, J. J.; Taniuchi, M.; Sobuz, S. U.; Haque, R.; et al. A Laboratory-Developed Taqman Array Card for Simultaneous Detection of 19 Enteropathogens. J. Clin. Microbiol. 2013, 51 (2), 472-480.

(41) Rachwal, P. A.; Rose, H. L.; Cox, V.; Lukaszewski, R. A.; Murch, A. L.; Weller, S. A. The Potential of TaqMan Array Cards for Detection of Multiple Biological Agents by Real-Time PCR. PLoS One 2012, 7 (4), e35971.

(42) Liu, J.; Gratz, J.; Amour, C.; Nshama, R.; Walongo, T.; Maro, A.; Mduma, E.; Platts-Mills, J.; Boisen, N.; Nataro, J.; et al. Optimization of Quantitative PCR Methods for Enteropathogen Detection. PLoS One 2016, 11 (6), No. e0158199.

(43) Schreiner, M. Simple Poverty Scorecard Poverty-Assessment Tool Mozambique, 2013.

(44) Baraldi, A. N.; Enders, C. K. An Introduction to Modern Missing Data Analyses. J. Sch. Psychol. 2010, 48 (1), 5-37.

(45) Azur, M. J.; Stuart, E. A.; Frangakis, C.; Leaf, P. J. Multiple Imputation by Chained Equations: What Is It and How Does It Work? Int. J. Methods Psychiatr. Res. 2011, 20 (1), 40-49.

(46) Jakobsen, J. C.; Gluud, C.; Wetterslev, J.; Winkel, P. When and How Should Multiple Imputation Be Used for Handling Missing Data in Randomised Clinical Trials - A Practical Guide with Flowcharts. BMC Med. Res. Methodol. 2017, 17 (1), 162.

(47) Benjamini, Y.; Hochberg, Y. Controlling the False Discovery Rate: A Practical and Powerful Approach to Multiple Testing. J. $R$. Stat. Soc. Ser. B 1995, 57 (1), 289-300.

(48) Jaccard, P. Étude Comparative de La Distribution Florale Dans Une Portion Des Alpes et Des Jura. Bull. la Société vaudoise des Sci. Nat. 1901, 37, 547-579.

(49) Pehrsson, E. C.; Tsukayama, P.; Patel, S.; Mejia-Bautista, M.; Sosa-Soto, G.; Navarrete, K. M.; Calderon, M.; Cabrera, L.; HoyosArango, W.; Bertoli, M. T.; Berg, D. E.; Gilman, R. H.; Dantas, G. Interconnected Microbiomes and Resistomes in Low-Income Human Habitats. Nature 2016, 533, 212.

(50) Lax, S.; Smith, D. P.; Hampton-Marcell, J.; Owens, S. M.; Handley, K. M.; Scott, N. M.; Gibbons, S. M.; Larsen, P.; Shogan, B. D.; Weiss, S.; et al. Longitudinal Analysis of Microbial Interaction between Humans and the Indoor Environment. Science (Washington, DC, U. S.) 2014, 345 (6200), 1048-1052.

(51) Miller-Petrie, M. K.; Voigt, L.; McLennan, L.; Cairncross, S.; Jenkins, M. W. Infant and Young Child Feces Management and Enabling Products for Their Hygienic Collection, Transport, and Disposal in Cambodia. Am. J. Trop. Med. Hyg. 2016, 94 (2), 456-465.

(52) Pepper, I. L.; Gerba, C. P.; Gentry, T. J. Environmental Microbiology, 3rd ed.; Elsevier: New York, 2015.

(53) Feachem, R. G.; Bradley, D. J.; Hemda, G.; Mara, D. D. Sanitation and Disease: Health Aspects of Excreta and Waste-Water Management, 1st ed.; John Wiley and Sons: Chichester, West Sussex, 1983.

(54) Aw, T. Environmental Aspects and Features of Critical Pathogen Groups. In Global Water Pathogen Project; Michigan State University, 2019.

(55) Rose, J.; Jiménez-Cisneros, B.; Murphy, H. Persistence of Pathogens in Sewage and Other Water Types. In Global Water Pathogen Project; Michigan State University, 2019.

(56) Clarke, N. E.; Clements, A. C. A.; Doi, S. A.; Wang, D.; Campbell, S. J.; Gray, D.; Nery, S. V. Differential Effect of Mass Deworming and Targeted Deworming for Soil-Transmitted Helminth
Control in Children: A Systematic Review and Meta-Analysis. Lancet 2017, 389 (10066), 287-297.

(57) Yeager, J. G.; Ward, R. L. Effects of Moisture Content on LongTerm Survival and Regrowth of Bacteria in Wastewater Sludge. Appl. Environ. Microbiol. 1981, 41 (5), 1117-1122.

(58) Kotloff, K. L; Nataro, J. P; Blackwelder, W. C; Nasrin, D.; Farag, T. H; Panchalingam, S.; Wu, Y.; Sow, S. O; Sur, D.; Breiman, R. F; Faruque, A. S.; Zaidi, A. K.; Saha, D.; Alonso, P. L; Tamboura, B.; Sanogo, D.; Onwuchekwa, U.; Manna, B.; Ramamurthy, T.; Kanungo, S.; Ochieng, J. B; Omore, R.; Oundo, J. O; Hossain, A.; Das, S. K; Ahmed, S.; Qureshi, S.; Quadri, F.; Adegbola, R. A; Antonio, M.; Hossain, M J.; Akinsola, A.; Mandomando, I.; Nhampossa, T.; Acacio, S.; Biswas, K.; O'Reilly, C. E; Mintz, E. D; Berkeley, L. Y; Muhsen, K.; Sommerfelt, H.; Robins-Browne, R. M; Levine, M. M Burden and Aetiology of Diarrhoeal Disease in Infants and Young Children in Developing Countries (the Global Enteric Multicenter Study, GEMS): A Prospective, Case-Control Study. Lancet 2013, 382, 209-222.

(59) Lopman, B.; Gastañaduy, P.; Park, G. W.; Hall, A. J.; Parashar, U. D.; Vinjé, J. Environmental Transmission of Norovirus Gastroenteritis. Curr. Opin. Virol. 2012, 2, 96-102.

(60) Peccia, J.; Zulli, A.; Brackney, D. E.; Grubaugh, N. D.; Kaplan, E. H.; Casanovas-Massana, A.; Ko, A. I.; Malik, A. A.; Wang, D.; Wang, M.; et al. SARS-CoV-2 RNA Concentrations in Primary Municipal Sewage Sludge as a Leading Indicator of COVID-19 Outbreak Dynamics. medRxiv, 2020. https://www.medrxiv.org/ content/10.1101/2020.05.19.20105999v2.

(61) Haas, C. N. Quantitative Microbial Risk Assessment (QMRA) and Molecular Biology - Paths to Integration. Environ. Sci. Technol. 2020, 54, 8539 . 